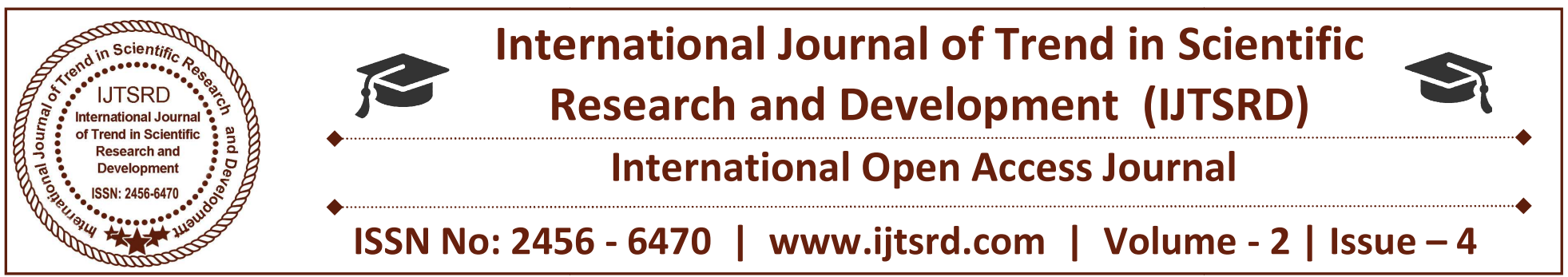

\title{
Single and Two Phase Pressure Drop in Fluid
}

\author{
Dhruvkumar Joshi, Upasna Sethi, Hardik Tekwani \\ Department of Mechanical Engineering, \\ Vadodara Institute of Engineering, Vadodara, Gujarat, India
}

\begin{abstract}
Pressure drop is of paramount importance in a fluid flow. Single phase pressure drop occurs in a pure liquid or pure gas flow. Two phase pressure drop occurs in phase changing equipments like evaporators and condensers of refrigeration air conditioning plants and heat pumps. Maximum two/ three types of pressure drop (frictional, gravitational and acceleration) can occur in a single or two phase flow. In each case, pressure drop take place in straight pipes. Several empirical equations and correlations have been developed and compared for the pressure drop. Consequently well planned pipe layout and judicious selection of proper pipe material, pipe fittings and valves will result in reducing the overall pressure drop which in turn will reduce the running cost.
\end{abstract}

Keywords: Pressure drop, Single phase, Two phase, Frictional, Gravitational, Acceleration

\section{INTRODUCTION}

It is difference of pressure between two points in a fluid flow. These two points can be at a horizontal level or at different levels. Flow can be only liquid flow or only gas flow or mixed flow (two phase flow). The temperature difference is the driving force for heat transfer. Voltage difference is the driving force for current flow. Concentration difference is the driving force for mass transfer. Similarly pressure difference is the driving force for the flow of a fluid. Pressure drop is extremely important in fluid flow. It should be small otherwise it increases the cost of operation of the fluid flow. Pressure drop is present in a straight pipe and also across various types of pipe fittings and valves. Only after careful analysis, judicious selection is made regarding pipe material, pipe roughness, pipe layout and orientation, fittings and valves. In this review, pressure drop analysis has been limited to a single phase flow as well as in a two phase flow

\section{TYPES OF PRESSURE DROP}

There are three types of pressure drop. These are

- Frictional pressure drop

- Gravitational pressure drop

- Acceleration pressure drop in an evaporator or condenser

\section{IIINE SINGLE PHASE LIQUID FLOW FRICTIONAL PRESSURE DROP IN A STRAIGHT PIPE}

It is considered under laminar and turbulent flows.

a. Laminar Flow - Single Phase Frictional Pressure Drop in a Laminar Flow is found with Darcy Weisbach Equation which is applicable only for liquids with fully developed and steady flow. First head loss $(\Delta \mathrm{h})$ is calculated and then pressure drop $(\Delta p)$ is found. Darcy-Weisbach equation for frictional head loss, $6 \mathrm{hf}$, is

$\Delta \mathrm{hf}=\mathrm{f} \mathrm{LV}^{2} / 2 \mathrm{gD}$

Pressure Drop $=$ Head Loss x q x g.

b. Turbulent Flow - Darcy-Weisbach Equation is used for a turbulent flow as well. But here the friction factor is a function of Reynolds number and pipe roughness. The friction factor is found 
from the Cole Brook relation.

$\mathrm{f}-\mathrm{l}=-2 \log ((2.5 \mathrm{l} /(\operatorname{Re} \mathrm{fl} / 2)+(\mathrm{k} / \mathrm{D}) \times 0.269))$

' $\mathrm{f}$ ' exist on both sides of the equation and can be found only by an iterative procedure. Here ' $k$ ' is the roughness of the pipe.

\section{SINGLE PHASE GAS FLOW FRICTIONAL PRESSURE DROP}

In compressible fluids (gases and vapors), there is a significant increase in velocity due to pressure decreases (Expansion) and hence requires a different equation as compared to that for liquids.

$\left(\mathrm{pl}^{2}-\mathrm{p} 2^{2}\right) / 2 \mathrm{pl}=\mathrm{f}(\mathrm{L} / \mathrm{D}) \mathrm{ql}\left(\mathrm{Vav}^{2} / 2\right)(\operatorname{tav} / \mathrm{tl})$

$\operatorname{tav}=(\mathrm{tl}+\mathrm{t} 2) / 2$

\section{TWO PHASE PRESSURE DROP}

Two phase pressure drop [1-22] in a horizontal pipe can be found by either of the two methods.

A. Homogeneous flow method - Firstly the two phase flow is considered as total liquid flow. Now the pressure drop is calculated for liquid flow only. Then the two phase pressure drop is found by multiplying the liquid phase pressure drop by a two phase multiplier.

B. Separated flow model - Relatively more common. Using this method, many correlations have been developed for the two phase pressure drop. Some of these are

a) Lockhart Martinelli Nelson Correlation [1]

b) Friedel Correlation

c) Gronnerud Correlation

d) Chawla Correlation

e) Müller Steinhagen and Heck Correlation

f) Present author correlations for mixtures of refrigerants

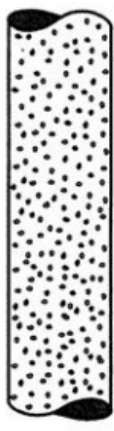

Bubbly

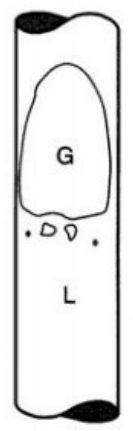

Slug

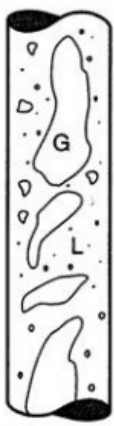

Churn

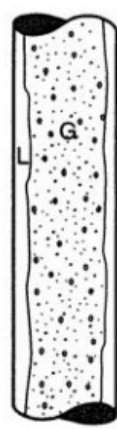

Annular

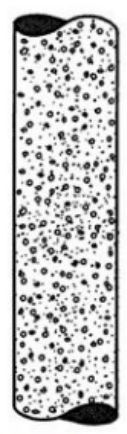

Mist flow
Fig: Two Phase flow in vertical pipe

\section{COMPARISON OF TWO PHASE PRESSURE DROP CORRELATIONS}

(a) Whalley compared [22] the above correlations based on 25000 experimental data points and concluded the followings:

(i) For $\left(\mu_{\mathrm{L}} / \mu_{\mathrm{G}}\right)<1000$ and mass flux $<$ $2000 \mathrm{~kg} / \mathrm{m}^{2} \mathrm{~s}$, the Friedel correlation [4] is better than other correlations in agreement with the experimental data

(ii) For $\left(\mu_{\mathrm{L}} / \mu_{\mathrm{G}}\right)>1000$ and mass flux $>100$ $\mathrm{kg} / \mathrm{m}^{2} \mathrm{~s}$, the Chisholm correlation [3] is better than other correlations in agreement with the experimental data

(iii) For $\left(\mu_{\mathrm{L}} / \mu_{\mathrm{G}}\right)>1000$ and mass flux $<100$ $\mathrm{kg} / \mathrm{m}^{2} \mathrm{~s}$, the Lockhart-Martinelli correlation [1] is better than other correlations in agreement with the experimental data

(iv) For $\left(\mu_{\mathrm{L}}<\mu_{\mathrm{G}}\right)<1000$, the Friedel correlation(4) is better than other correlations in agreement with the experimental data for most of the fluids

(b) Tribbe and Muller- Steinhagen [14] compared number of leading correlations for two phase frictional pressure drop based on a very large experimental data and found that Muller Steinhagen and Heck Correlation [8] was the best correlation for air-oil, air-water, water steam and many refrigerant systems.

(c) Ould Didi, Kattan and Thome [16] compared number of leading correlations for two phase frictional pressure drop based on a very large experimental data and found that MullerSteinhagen and Heck Correlation [8] was the best correlation specially R-134a, R-123, R-402A, R404-A and R-502 an azeotrope.

The two phase frictional pressure drop has been found to be a function of mixture composition. The 
authors have successfully developed a correlation on the basis of Chisholm and Sutherland method, which has been found to give better agreement that the earlier reported method [1] based on MartinelliNelson correlation. The developed correlations [6] are

$6 \mathrm{pf} / 6 \mathrm{pf}, \mathrm{C}-\mathrm{S}=1.44(1+\mathrm{C})^{1.293}$

$6 \mathrm{pf} / 6 \mathrm{pf}, \mathrm{C}-\mathrm{S}=1.46(\mathrm{l}-\mathrm{C})^{-1.006}$

Where $\mathrm{C}$ is the concentration by mass of $\mathrm{R}-13$

The drawbacks of these correlations are that these do not allow extrapolation of pressure drops to high concentrations of R-13, say above 25 per cent.

The mean and standard deviations for the developed correlations were found to be as given below:

Table - Mean and Standard Deviations

\begin{tabular}{|l|l|l|}
\hline Equatio & Mean & Standard \\
\hline 1. & -2.05 & 17.31 \\
\hline 2. & -2.05 & 17.34 \\
\hline
\end{tabular}

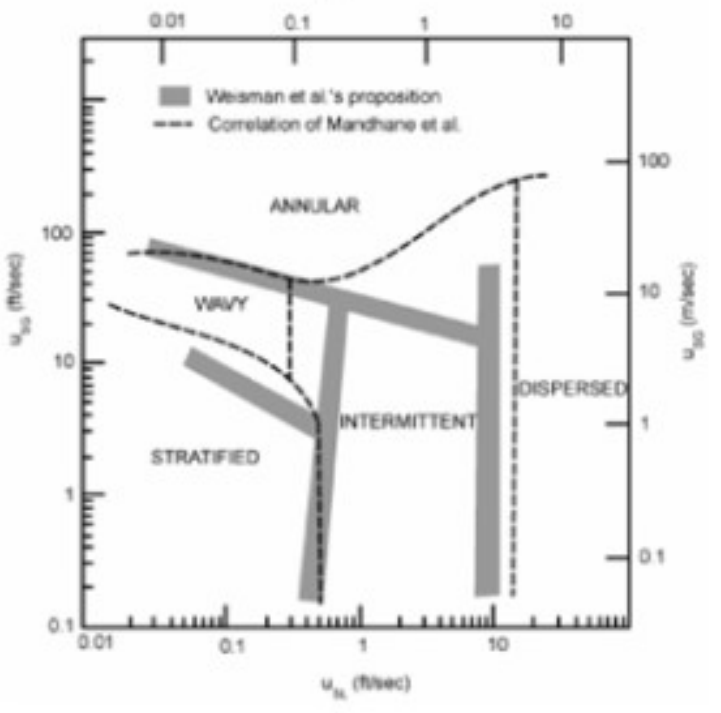

Fig: Flow patterns map for air-water flow in vertical pipes

\section{CONCLUSION}

Single phase and two phase pressure drop is a critical parameter in the design of a pipe flow as well as in the selection of a pipe fitting and a valve. Therefore accurate prediction of pressure drop is of utmost importance. Single phase pressure drop is estimated using Darcy equation. Two phase pressure drop is estimated by using widely accepted empirical equations. Two phase pressure drop is extremely importance in the design of phase changing equipment mainly evaporators and condensers used in refrigeration, air conditioning and heating pumps. Thus design engineer must know the pressure drop to a high degree of accuracy to ensure proper pipe design and selection of a pipe fitting and a valve. Pressure drop and flow rate are dependent on one another. The higher is the flow rate, the greater will be the pressure drop and vice versa. In every application, pressure drop must be kept to a minimum possible level in order to reduce the running cost of pipe flow. It can be achieved by the judicious selection of the pipe material, pipe roughness, pipe layout, pipe orientation, pipe fittings and valves

\section{REFERENCES}

1) R. W. Lockhart and R. C. Martinelli, Proposed correlation of data for isothermal two-phase twocomponent flow in pipes, Chem. Eng. Progr., 4.5 (1949) 39-48.

2) J.G.Collier, Convective Boiling and Condensation, McGraw Hill, New York, (1969).

3) Chisholm, Pressure gradients due to friction during the flow of evaporating two-phase mixtures in smooth tubes and channels, ht. J. Heat Mass Transfer, 16 (1973) 347-358

4) L. Friedel, Improved friction pressure drop correlations for horizontal and vertical two-phase flow, 3R Znt., 18 (7) (1979) 485-491.

5) D.R.H. Beattie, P.B. Whalley, A simple two phase frictional pressure drop calculation method, Int. J. Multiphase Flow 8 (1982) 83-87.

6) L.C.Singal, C.P.Sharma and H.K.Varma, "Pressure Drop During Forced Convection Boiling of Binary Refrigerant Mixtures" Int J. Multiphase Flow, Vol.9, No.3, (1983), 309-323.

7) L.C.Singal, C.P.Sharma and H.K.Varma, "Prediction of Pressure Drop During Forced Convection Boiling of Mixtures of Refrigerants 13 and 12" Int Comm. Heat Mass Transfer,Vol.10,(1983)545-554

8) H. Müller Steinhagan, K. Heck, A simple friction pressure drop correlation for two phase flow in pipes, C.E.P. 20 (1986) 297-308.

9) M.E.G. Ferguson, P.L. Spedding, Measurement and prediction of pressure drop in two phase flow, J. Chem. Technol. Biotechnol. 62 (1995) 262-278. 
10) A.L. Souza, M.W. Pimenta, Prediction of Pressure Drop during Horizontal Two Phase Flow of Pure and Mixed Refrigerants. ASME Conf Cavitation and Multiphase Flows, HTD, vol. 21O, 1995, p. 161.

11) K. Mishima, T. Hibiki, Some characteristics of air-water two phase flow in small diameter vertical tubes, Int. J. Multiphase Flow 22 (1996) $703-712$.

12) K.A. Triplett, S.M. Ghiaasiaan, S.I. Abdel-Khalik, A. Lemouel, B.N. McCord, Gas- liquid two-phase flow in microchannels. Part II: void fraction and pressure drop, Int. J. Multiphase Flow 25 (1999) 395-410.

13) C.C. Wang, K.S. Yang, Y.J. Chang, D.C. Lu, Characteristics of air-water two-phase flow in a 3 $\mathrm{mm}$ smooth tube, The Canadian J. Chem. Eng. 78 (2000) 1O11- 1016.

14) Tribbe. C., Müller-Steinhagen. H. 2000. An Evaluation of the Performance of Phenomenological models for Predicting Pressure Gradient during Gas Liquid Flow in Horizontal Pipelines. Int. J. Multiphase Flow. 26: 1019-1036.

15) C.C. Wang, S.K. Chiang, Y.J. Chang, T.S. Chung, Two-phase flow resistance of Refrigerants R-22, R410A and R407C in small diameter tubes, Trans. IChemE Part A 79 (2001) 553-560.

16) M.B. Ould Didi, N. Kattan, J.R. Thome"Prediction of Two-Phase Pressure Gradients of Refrigerants in Horizontal Tubes"International Journal of Refrgieration, Vol 25, pp. 935-947, 2002

17) Kawahara, P.M.Y. Chung, M. Kawaji, Investigation of two-phase flow pattern, void fraction and pressure drop in a micro channel, Int. J. Multiphase Flow 28 (2002) 1411-1435.

18) M.M. Awad, Y.S. Muzychka, Bounds on twophase flow part I-frictional pressure gradient in circular pipes, in: Proceedings of ASME- IMECE (2005).

19) Two Phase Pressure Drop, Engineering Data Book III, Chapter 13, VOLVERINE TUBE, INC. (engineering Thermal Innovation) (2006).

20) K. Dutkowski, Two-phase pressure drop of airwater in mini channels, Int. J. Heat Mass Transfer 52 (2009) 5185-5192.

21) I.W. Zhang, T. Hibiki, K. Mishima, Correlations of two-phase frictional pressure drop and void fraction in mini-channel, Int. J. Heat Mass Transfer 53 (2010) 453-465.

22) Chapter 13, Two Phase Pressure Drops, Engineering Data Book III, WOLVERINE TUBE, INC. (Engineering Thermal Innovation).

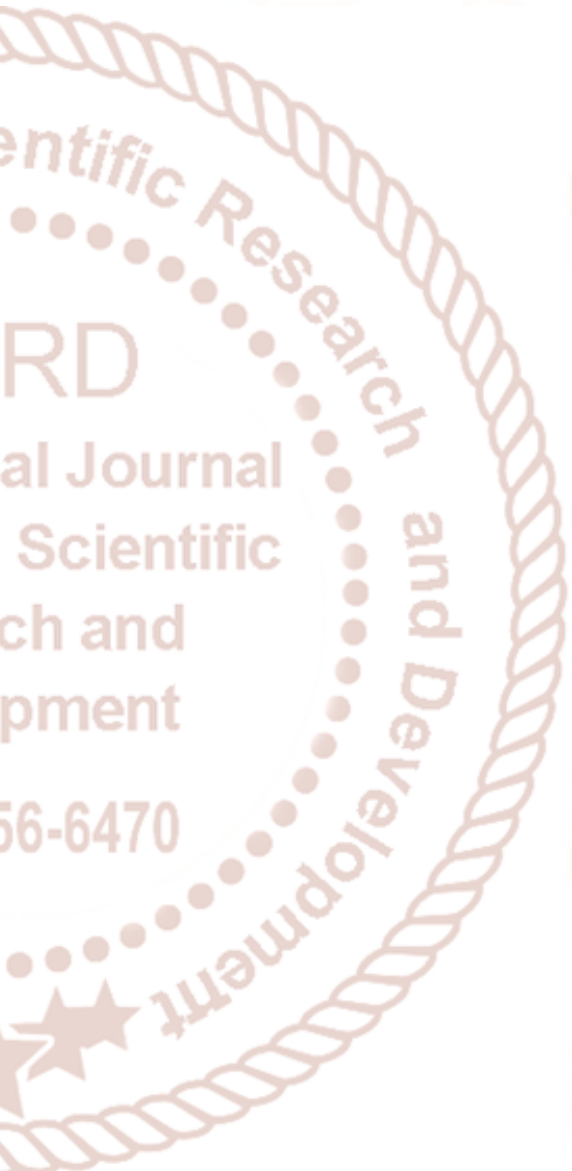

